RESENDE, J.M.; CHITARRA, M.I.F.; MALUF, W.R.; CHITARRA, A.B.; SAGGIN JÚNIOR, O.J. Atividade de enzimas pectinametilesterase e poligalacturonase durante o amadurecimento de tomates do grupo multilocular. Horticultura Brasileira, Brasília, v.22, n.2, p.206-212, abril-junho 2004.

\title{
Atividade de enzimas pectinametilesterase e poligalacturonase durante 0 amadurecimento de tomates do grupo multilocular
}

\author{
Josane Maria Resende ${ }^{1}$; Maria Isabel F. Chitarra ${ }^{1}$; Wilson Roberto Maluf ${ }^{2}$; Adimilson Bosco Chitarra ${ }^{1}$; \\ Orivaldo José Saggin Júnior ${ }^{3}$ \\ ${ }^{1}$ UFLA-DCA, ${ }^{2}$ UFLA-DAG, C. Postal 37, 37200-000 Lavras-MG, E-mail: josane.resende@agr.unicamp.br; ${ }^{3}$ Embrapa Agrobiologia, C. \\ Postal 74.505, 23851-970 Seropédica-RJ
}

\section{RESUMO}

Mediu-se a atividade das enzimas pectinametilesterase (PME) e poligalacturonase (PG) em frutos de tomate do grupo multilocular em diferentes estádios de maturação e correlacionou-se com mudanças na textura, pectinas e licopeno. Os tomates foram colhidos no estádio verde-maturo e colocados a amadurecer em recinto com umidade relativa de $85-90 \%$ e temperatura ambiente de $20^{\circ} \mathrm{C} \pm 2$. Durante o armazenamento, foram retiradas amostras nos estádios verde-maturo, "de vez", maduro e vermelho-maduro para determinar a atividade enzimática. As outras características foram analisadas somente quando os frutos atingiram o estádio vermelho-maduro. Dentre os genótipos avaliados, três híbridos, H3: $\mathrm{F}_{1}$ (BPX 308B hv $x$ Stevens), H8: $\mathrm{F}_{1}$ (BPX 308B hv $x$ Piedmont) e H1: $\mathrm{F}_{1}(\mathrm{BPX}$ 308B hv $x$ BPX-127H) sobressaíram-se com melhores características para o consumo ao natural, quando comparado às testemunhas, por apresentarem menor atividade das enzimas PME e PG, o que reduziu a despolimerização e solubilização das pectinas resultando em maior textura. As maiores espessuras da polpa e menores números de lóculos também contribuíram para aumentar a textura do fruto melhorando a vida-de-prateleira e a qualidade dos frutos. A baixa atividade da enzima PG não influenciou o desenvolvimento da cor, atributo considerado importante na aceitação do fruto pelo consumidor. O híbrido H1: $\mathrm{F}_{1}$ (BPX 308B hv $x$ BPX-127H), que contém o gene alc em heterozigose, o qual condiciona maior conservação pós-colheita, foi o terceiro melhor híbrido para consumo, não apresentando efeito detrimental na coloração, sugerindo que o gene alc em heterozigose pode ser uma alternativa viável para o melhoramento genético do tomateiro visando a melhor conservação póscolheita.

Palavras-chave: Lycopersicon esculentum, híbridos $\mathrm{F}_{1}$, alcobaça, Crimson, high pigment, melhoramento genético, amaciamento, conservação pós-colheita.

\section{ABSTRACT}

Activity of the enzymes pectinmetylesterase and polygalacturonase during the ripening of tomatoes of the multilocular group

The activity of the enzymes pectinametylesterase (PME) and polygalacturonase (PG) was measured in tomato fruits of the multilocular group at various maturation stages, to obtain the correlation to changes in texture, pectin and lycopene. Fruits were harvested at the mature-green stage and ripened in a room with 85$90 \%$ relative humidity and $20^{\circ} \mathrm{C} \pm 2$ room temperature. Throughout storage, samples were taken to assess enzymes activity of PME and PG at the maturation stages: mature green, breaker, ripe and redripe. The other variables were surveyed only after the red-ripe stage of fruits. Among the evaluated genotypes, three hybrids H3: $\mathrm{F}_{1}$ (BPX 308B hv $x$ Stevens), H8: $\mathrm{F}_{1}$ (BPX 308B hv $x$ Piedmont) and H1: $\mathrm{F}_{1}$ (BPX 308B hv $x$ BPX-127H) stood out with best characteristics for natural consumption when compared to control, showing the least enzymes activities of PME and PG which led to a decrease in depolymerization and solubilization of pectin, causing an increased texture. In addition, larger pulp thickness and smaller numbers of locules of these hybrids also contributed to the texture increase, improving shelf life and fruit quality. The low activity of the enzyme PG did not affect the development of color, an important trait for acceptance of the fruit by consumers. The hybrid H1: $\mathrm{F}_{1}$ (BPX 308B hv $x$ BPX-127H), containing the alc gene in heterozigosis, which improves post-harvest conservation, was the third best hybrid for consumption. Presenting the alc gene in heterozigosis and, without detrimental effect in coloration, this hybrid may be a viable option for tomato plant breeders to improve post-harvest preservation.

Keywords: Lycopersicon esculentum, $\mathrm{F}_{1}$ hybrids, alcobaça, Crimson, high pigment, plant breeding, softness, post harvest conservation.

(Recebido para publicação em 14 de outubro de 2003 e aceito em 3 de dezembro de 2004)

\begin{abstract}
A textura é um importante fator de qualidade em tomates para o consumo ao natural, pois indica a tolerância do fruto ao transporte e manuseio durante a colheita e comercialização. Contudo, o mecanismo pelo qual os frutos amaciam não é completamente entendido. Tem sido sugerido que decréscimos na firmeza durante o amadurecimento de frutos são devido a alterações nas características dos polissacarídeos da lamela média da parede celular, cujos principais componentes são as subs-
\end{abstract}

tâncias pécticas (Batisse et al., 1994). Estas são as principais responsáveis pelas mudanças de textura. A firmeza também depende da espessura da casca, textura da polpa e estrutura locular dos frutos (Mabbett, 1989). Desta forma, a perda progressiva de textura durante a maturação do tomate tem sido atribuída à redução na espessura das paredes celulares e da força coesiva que as mantém unidas, pela decomposição de protopectinas, celuloses, hemiceluloses e amido ( Fisher e Bennett, 1991)
Embora várias hidrolases da parede celular tenham sido implicadas no amaciamento do fruto, especial atenção tem sido dada à degradação de poliuronídeos. O papel das enzimas pectolíticas, pectinametilesterase (PME) e poligalacturonase $(\mathrm{PG})$ durante a maturação do tomate tem sido extensivamente investigado em genética, bioquímica e níveis de expressão de genes (Fischer e Bennett, 1991).

A PME tem papel importante no amaciamento de frutos pelo aumento in 
Tabela 1. Constituição genotípica dos híbridos de tomates, relativa aos locos alcobaça, crimson e high pigment empregados no experimento. Lavras-MG, UFLA, 1995.

\begin{tabular}{|c|c|c|c|}
\hline \multirow{2}{*}{ Híbridos } & \multicolumn{3}{|c|}{ Genótipos nos locos } \\
\hline & Alcobaça & Crimson & High pigment \\
\hline H1: F1 (BPX 308B hv x linhagem BPX-127H) & $+/$ alc & $+\log ^{c}$ & $+1+$ \\
\hline H2: F1 (BPX 308B hv x linhagem BPX-105H) & $+1+$ & $\operatorname{og}^{c} / \operatorname{og}^{c}$ & $+/ \mathrm{hp}$ \\
\hline H3: F1 (BPX 308B hv x cultivar Stevens) & $+1+$ & $+\log ^{c}$ & $+1+$ \\
\hline H4: F1 (BPX 308B hv x cultivar Rotam- 4) & $+1+$ & $+\log c$ & $+1+$ \\
\hline H5: F1 (BPX 308B hv x linhagem BHRS-2-3) & $+1+$ & $+\log ^{c}$ & $+1+$ \\
\hline H6: F1 (BPX 308B hv x cultivar Flórida 1B) & $+1+$ & $+\log c$ & $+1+$ \\
\hline H7: F1 (BPX 308B hv x Tropicana) & $+1+$ & $+\log c$ & $+1+$ \\
\hline H8: F1 (BPX 308B hv x cultivar Piedmont) & $+1+$ & $+1 \operatorname{og}^{\circ}$ & $+1+$ \\
\hline L.T.: Test.Tropicana-o.p. & $+1+$ & $+1+$ & $+1+$ \\
\hline O.F.: Test. O. Fukuju $\left(\mathrm{F}_{1}\right)$ & $+1+$ & $+1+$ & $+1+$ \\
\hline
\end{tabular}

$+/+$ : normal; +/ alc: heterozigoto para alcobaça; $\mathrm{og}^{\mathrm{c}} / \mathrm{og}^{\mathrm{c}}:$ homozigoto para crimson; $+/ \mathrm{og}^{\mathrm{c}}:$ heterozigoto para crimson $;+/ \mathrm{hp}$ : heterozigoto para high pigment.

vivo da suscetibilidade das pectinas à $\mathrm{PG}$ durante o amadurecimento (Koch e Nevins, 1989). Essa enzima catalisa a desmetilação do $\mathrm{C}_{6}$ do grupo carboxilíco dos resíduos de galacturosil, desesterificando-os. Assim, a PG só catalisa a hidrólise das ligações $\alpha, 1-4$ do ácido galacturônico quando desesterificados (Fischer e Bennett, 1991). Portanto, a hidrólise da pectina depende da ação da PME, que está presente em todos os estádios de desenvolvimento do tomate, porém, o aumento em sua atividade só ocorre durante o amadurecimento (Pressey e Avants, 1982).

A PG cataliza a hidrólise das ligações $\alpha$ 1-4 entre os resíduos de ácido galacturônico da cadeia de pectina (Fischer e Bennett, 1991). Sua atividade tem sido identificada em vários frutos durante o amadurecimento, e se correlaciona com aumento de pectinas solúveis e amaciamento durante o amadurecimento (Ahrens e Huber, 1990).

Mutantes de tomates com os genes rin, nor, $\mathrm{Nr}$ ou alc, reduzem a transcrição da PG, provavelmente por não acumular o RNA mensageiro que a codifica. Porém, esses genes podem induzir alguns efeitos não desejáveis no sabor, aroma e na cor dos frutos (Mutchler et al., 1992). O entendimento da bioquímica do amaciamento de frutos com o amadurecimento poderão propiciar informações comerciais importantes, uma vez que frutos mais firmes poderão ser comercializados por períodos mais longos.
O objetivo do trabalho foi medir a atividade de enzimas PME e PG em tomates do grupo multilocular em quatro estádios de maturação (verde-maturo, "de vez", maduro e vermelho-maduro), e correlacionar com mudanças na textura, teores de pectinas e licopeno no fruto maduro.

\section{MATERIAL E MÉTODOS}

Os tratamentos foram constituídos por híbridos $\mathrm{F}_{1}$ experimentais de tomates do grupo multilocular e como testemunhas foram utilizados frutos da linhagem Tropicana (polinização aberta-op) e do híbrido comercial Ogata Fukuju (Tabela 1).

Os progenitores utilizados na obtenção dos híbridos possuíam as características:

Linhagem BPX-308B hv: progenitor feminino comum a todos os híbridos. Possui o gene $m s-35$ para macho esterilidade (fortemente ligado ao gene aa) que, quando em homozigose, condiciona o fenótipo hipocótilo verde, o que facilita a identificação da macho esterilidade na fase de plântula. Possui também o gene $\operatorname{og}^{c}$ (“old gold crimson"), associado ao gene $s p^{+}$que, em homozigose condicionam maior teor de licopeno nos frutos e hábito de crescimento indeterminado, respectivamente.

Linhagem BPX-127H: homozigótica para o locos alcobaça que condiciona maior conservação pós-colheita dos frutos. É isogênica à cultivar americana Tropic.

Linhagem BPX-105H: resistente a nematóides e homozigótica para os genes $o g^{c}$ ("old gold crimson") e $h p$ ("high pigment"), que condicionam maior teor de licopeno nos frutos maduros e, no caso do $h p$, também maior teor de b-caroteno.

Cultivar Stevens: procedente da África do Sul, com resistência ao vírus do grupo vira-cabeça (Topvirus).

Cultivar Rotam-4: procedente da África do Sul, é resistente a nematóides e murcha bacteriana.

Linhagem BHRS-2-3: procedente da Austrália, é resistente às raças 1, 2 e 3 de Fusarium oxysporum f. sp lycopersici (Sacc.) Synd e Hans.

Cultivar Flórida1-B: procedente da Universidade da Flórida (EUA).

Linhagem Tropicana: resistente a nematóides e isogênica à cultivar americana Tropic, portanto, de constituição genotípica semelhante à linhagem BPX127H. Usada também como cultivar de polinização aberta (op).

Cultivar Piedmont: procedente da Carolina do Norte (EUA), possui o gene $V e$, que confere resistência à raça 1 de Verticillium dahliae Kleb, e o gene I-2, que confere resistência às raças 1 e 2 de Fusarium oxysporum f. sp lycopersici (Sacc.) Synd e Hans, além de apresentar resistência a todo tipo de rachadura 
do fruto, possui ainda o gene $u$ que confere maturação uniforme ao fruto, ausência de ombro verde (Gardner, 1985).

Ogata Fukuju: híbrido $F_{1}$ de origem japonesa usado como testemunha comercial, apresenta consistência do fruto maduro muito mole, mas de bom aspecto e tamanho médio.

Utilizou-se delineamento em blocos casualizados, com três repetições. As unidades experimentais foram constituídas por sete frutos de cada um dos dez tratamentos. Os frutos foram acondicionados em bandejas plásticas $(25 \times 30 \mathrm{~cm})$ e mantidos em ambiente com temperatura de $20^{\circ} \mathrm{C} \pm 2$ e umidade relativa entre $85-90 \%$. Foram analisados quatro frutos de cada unidade experimental quanto à sua atividade de PME e PG nos estádios verde-maturo, "de vez", maduro e vermelho-maduro (Pratt e Workman, 1962). Os três frutos restantes foram deixados para atingir o estádio vermelho-maduro para as análises de espessura da polpa, número de lóculos, textura, licopeno e pectinas.

Foram avaliadas as variáveis: $\mathbf{N}^{\mathbf{0}} \mathbf{d e}$ lóculos (determinado visualmente por meio de contagem); Espessura da polpa (em $\mathrm{cm}$, determinada em quatro pontos distintos, após o corte transversal do fruto); Textura (medida nos frutos após retirar uma pequena porção da casca, por meio de penetrômetro Magness-Tayler, com "Pluger" de 7,94 mm de diâmetro; resultados expressos em Newtons após a multiplicação pelo fator 4,11; os maiores valores indicam frutos mais firmes); Licopeno (extraído e determinado segundo técnica descrita por Mencarelli e Saltveit Jr. (1988); calculado usando o coeficiente de extinção molecular de $17,02 \times 10^{4}$ mol.cm $\mathrm{cm}^{-1}$; resultados expressos em mg de licopeno. $\mathrm{g}^{-1}$ de massa fresca); Pectina total e solúvel (extraídas segundo técnica descrita por McCready e McComb (1952), e determinadas colorimetricamente conforme técnica modificada por Bitter e Muir (1962); resultados expressos em $\mathrm{mg}$ de ácido galacturônico/100g de fruto); Atividade enzimática (os extratos brutos das enzimas foram obtidos segundo metodologia descrita por Pressey e Avants (1982) e Jen e Robinson (1984)); $A$ atividade da PME foi medida usando-se uma modificação do método de
Rouse e Atikins (1955), citados por Jen e Robinson (1984). Uma unidade de atividade de PME foi definida como a quantidade de enzima capaz de catalisar a desmetilação de pectina correspondente ao consumo de um nanomol de $\mathrm{NaOH}$ por dez minutos. A atividade da PG foi determinada pela incubação do extrato enzimático com ácido poligalacturônico (substrato) por três horas a $30^{\circ} \mathrm{C}$. Os açúcares redutores liberados após cessada a atividade enzimática foram doseados pelo método de Nelson (1944). Uma unidade de atividade de PG foi definida como a quantidade de enzima capaz de catalisar a formação de 1 nanomol de açúcar redutor por minuto sob as condições do ensaio.

Os dados obtidos foram submetidos à análise de variância e quando houve significância pelo teste de F, as médias foram testadas pelo teste de Duncan a $5 \%$ utilizando o programa SANEST (Sarriés et al., 1992).

\section{RESULTADOS E DISCUSSÃO}

O número de lóculos foi maior para o híbrido $\mathrm{H} 2$ e a testemunha Ogata Fukuju, indicando que o melhoramento do tomateiro multilocular obteve sucesso na redução do número de lóculos, particularmente dos híbridos $\mathrm{H} 8$ e $\mathrm{H} 3$ (Tabela 2). Os híbridos H8, H3 e H4 se sobressaíram apresentando maior espessura da polpa quando comparados aos demais, entretanto todas cultivares apresentaram maior espessura da polpa do que a testemunha Ogata Fukuju (Tabela 2). Ambas as características são desejáveis no melhoramento do tomate por contribuírem no aumento da textura dos frutos e consequentemente na sua vidade-prateleira. Todas cultivares, com exceção do híbrido H2, apresentaram textura maior que a testemunha Ogata Fukuju; este aumento foi mais evidente nos híbridos H8, H3 e H4 (Tabela 2). A textura do tomate é influenciada pela espessura da casca, firmeza da polpa e pela estrutura interna do fruto, ou seja, a relação pericarpo/material placentário (Mabbett, 1989). Assim, a maior textura dos híbridos $\mathrm{H} 3$ e $\mathrm{H} 8$ pode ser explicada, em parte, pela maior espessura da polpa e menor número de lóculos, entretanto a superioridade do híbrido $\mathrm{H} 1$ sobre o híbrido $\mathrm{H} 7$ pode ser atribuída a ação do gene alcobaça em heterozigose $(+/ a l c)$ no primeiro, uma vez que ambos possuem constituição genotípica semelhante, demonstrando que esse gene foi efetivo em aumentar a vida-de-prateleira desse híbrido. Mutschler et al. (1992) trabalhando com híbridos de tomate heterozigotos para alc, obtiveram aumento de $60 \%$ na vidade-prateleira em relação à linhagens de tomates de amadurecimento normal, além de maior firmeza dos frutos.

Além da estrutura locular e espessura da polpa, a ausência da rápida síntese da parede celular (Mitcham et al., 1991) que ocorre em frutos com perfil diferente de amadurecimento (climatério respiratório atrasado, redução no pico de etileno e redução na atividade da enzima PG) (Lobo et al., 1984), poderia explicar porque híbridos como H3 e H8 não perdem a firmeza tão rapidamente quanto as testemunhas. Essa seria outra possível explicação para a manutenção da textura nesses híbridos. Segundo Tong e Gross, (1990), a rápida aceleração na síntese da parede celular, que ocorre em tomates de amadurecimento normal, pode resultar na liberação de fragmentos da parede celular biologicamente ativos, com resíduos de galactosil de baixo peso molecular, que ocorrem antes do aumento inicial do ácido carboxílico 1-amino ciclopropano e etileno, os quais podem modificar a estrutura da parede celular levando a um rápido amaciamento do tecido.

Todas cultivares avaliadas apresentaram maiores teores de licopeno do que as testemunhas (Tabela 2). O híbrido $\mathrm{H} 2$, homozigoto para os genes $\operatorname{og}^{c} \mathrm{e}$ heterozigoto para $h p$ apresentou maior teor de licopeno, o que se esperava de um material $\operatorname{og}^{c} / \operatorname{og}^{c}$. No entanto, dois outros híbridos, o H1 e H5,

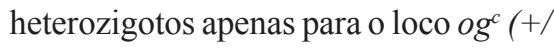
$\left.o g^{c}\right)$, também apresentaram altos teores de licopeno, o que demonstra que em determinadas constituições genotípicas o locos em heterozigose $\left(+/ \log ^{c}\right)$ também pode apresentar excelente coloração. Além disso o híbrido H1 que é heterozigoto para locos alc (+/alc) apresentou excelente pigmentação, demonstrando que o gene alc em heterozigose 
Atividade de enzimas pectinametilesterase e poligalacturonase durante o amadurecimento de tomates do grupo multilocular

Tabela 2. Número de lóculos, espessura de polpa, textura, licopeno, pectina total, pectina solúvel e relação pectina solúvel/pectina total de híbridos de tomate do grupo multilocular. Lavras-MG, UFLA, 1995.

\begin{tabular}{|c|c|c|c|c|c|c|c|}
\hline Híbridos & Lóculos $\left(\mathrm{N}^{\circ}\right)$ & $\begin{array}{c}\text { Esp. Polpa } \\
(\mathrm{mm})\end{array}$ & Textura (N) & Licopeno $^{11}$ & Pect. Total) ${ }^{/ 2}$ & Pect. Solúvel/2 & $\begin{array}{c}\text { Pect. solúvel/Total } \\
(\%)\end{array}$ \\
\hline $\mathrm{H} 1$ & $5,8 a b$ & $5,8 \mathrm{bcd}$ & $15,2 \mathrm{abc}$ & $89,08 a$ & $825,63 a b c$ & $227,46 f$ & $27,63 \mathrm{~cd}$ \\
\hline $\mathrm{H} 2$ & $6,9 a$ & $4,9 \mathrm{de}$ & $10,5 \mathrm{~cd}$ & $87,21 a b$ & $722,67 \mathrm{~cd}$ & $258,24 \mathrm{~cd}$ & $36,18 b$ \\
\hline H3 & $3,7 c$ & $6,7 a b$ & $17,6 a$ & $77,05 \mathrm{c}$ & $925,42 a b$ & $194,61 \mathrm{~h}$ & $21,60 d$ \\
\hline $\mathrm{H} 4$ & $5,0 b c$ & $6,4 a b c$ & $12,7 a b c$ & $75,07 c$ & $746,18 \mathrm{bcd}$ & $266,38 \mathrm{c}$ & $35,71 b$ \\
\hline H5 & $5,1 \mathrm{bc}$ & $5,7 \mathrm{~cd}$ & $15,2 a b c$ & $86,0 a b$ & $852,96 a b c$ & $249,82 d e$ & $30,02 b c$ \\
\hline $\mathrm{H} 6$ & $5,9 a b$ & $5,6 \mathrm{~cd}$ & $12,9 a b c$ & $84,3 b$ & $927,33 a b$ & $246,68 \mathrm{e}$ & $26,83 \mathrm{~cd}$ \\
\hline $\mathrm{H} 7$ & $5,1 \mathrm{bc}$ & $5,5 \mathrm{cde}$ & $12,3 b c$ & $78,06 c$ & $611,44 d$ & $278,12 b$ & $45,68 a$ \\
\hline $\mathrm{H} 8$ & $4,2 \mathrm{c}$ & $6,8 a$ & $16,3 a b$ & $77,97 \mathrm{c}$ & $996,61 a$ & $214,40 \mathrm{~g}$ & $21,52 d$ \\
\hline L.T. & $6,4 a b$ & $4,8 \mathrm{e}$ & $13,7 a b c$ & $64,42 d$ & $758,90 \mathrm{bcd}$ & $254,23 \mathrm{~cd}$ & $33,52 b c$ \\
\hline O.F. & $7,3 a$ & $3,0 f$ & $6,4 d$ & $53,15 \mathrm{e}$ & $772,88 \mathrm{bcd}$ & $370,68 a$ & $48,09 a$ \\
\hline
\end{tabular}

Médias seguidas de mesma letra nas colunas não diferem entre si pelo teste de Duncan 5\%.

${ }^{1 /}$ Licopeno em $\mu \mathrm{g} \cdot \mathrm{g}^{-1}$ de fruto

${ }^{2 /}$ Pectina total e solúvel em mg de ácido galacturônico $.100 \mathrm{~g}^{-1}$ de fruto

não influencia negativamente a coloração, como o faz no homozigoto. Um possível efeito negativo do gene alc em heterozigose na coloração poderia ter sido amenizado pela presença do gene $\operatorname{og}^{c}$ em heterozigose $\left(+/ \operatorname{og}^{c}\right)$, associado ainda à atividade alta de PG nesse híbrido quando comparado ao híbrido $\mathrm{H} 7$, de constituição genotípica semelhante. Aly et al. (1986) e Mutschler et al. (1992) sugeriram que o aumento de atividade da enzima PG tem efeito positivo sobre o conteúdo de licopeno, por ser usualmente acumulada em paralelo com o pigmento durante o amadurecimento.

A faixa de licopeno obtida nos híbridos bem pigmentados $(75$ a $89 \mathrm{mg}$ de licopeno/ $\mathrm{g}$ de fruto fresco) encontra-se próxima àquelas obtidas por Souza et al. (1992) (72 a $98 \mu \mathrm{g} / \mathrm{g}$ de fruto fresco) em tomates crimson com alta pigmentação.

A cor, juntamente com a textura, são atributos importantes na aceitação do tomate pelo consumidor. Suas modificações durante o amadurecimento têm sido empregadas como indicadores da qualidade do fruto (Chitarra e Chitarra, 1990; Souza et al., 1992). Os resultados deste estudo indicam que progressos consideráveis foram obtidos com o melhoramento, nas cultivares avaliadas, mantendo uma cor adequada para consumo ao natural.

O híbrido $\mathrm{H} 8$ apresentou maior teor de pectina total que os híbridos $\mathrm{H} 2, \mathrm{H} 4$, $\mathrm{H} 7 \mathrm{e}$ as testemunhas (Tabela 2). Contudo, o híbrido $\mathrm{H} 1$ de constituição genotípica semelhante ao $\mathrm{H} 7$, apresentou teor de pectina total maior, um efeito do locos alc em heterozigose (+/alc) neste híbrido, em contraposição ao genótipo normal $(+/+)$ neste locos no híbrido H7. $\mathrm{O}$ alto conteúdo de pectina total das cultivares sugere que a atividade da PG é reduzida durante o amadurecimento, possivelmente pela imobilização parcial da enzima, retenção dela no citoplasma ou regulações secundárias, como verificado por Koch e Nevins (1990), que não constataram mudanças no conteúdo de pectinas totais durante o amadurecimento de tomates.

Todas as cultivares mostraram teor inferior de pectina solúvel ao do híbrido Ogata Fukuju. Esses resultados podem ser melhor visualizados quando transformados em valores percentuais relativos à pectina total (Tabela 2). Os híbridos $\mathrm{H} 3$ e H8 apresentaram menor porcentagem de pectina solúvel em relação à pectina total. $\mathrm{O}$ híbrido $\mathrm{H} 1$ apresentou teor de pectina total maior, pectina solúvel menor e relação pectina solúvel/pectina total menor quando comparado ao híbrido $\mathrm{H} 7$ de constituição genotípica semelhante, o que reflete a ação do locos alc em heterozigose no híbrido $\mathrm{H} 1$, sugerindo que o gene alc em heterozigose proporciona maior textura aos frutos.

Os resultados de pectina solúvel, estão de acordo com os obtidos para textura e atividade das enzimas PME e PG. As cultivares que apresentaram maior textura possuíam maior espessura de polpa, menor número de lóculos, menor teor de pectina solúvel e menores atividades das enzimas PME e PG nos estádios iniciais de maturação, propiciando frutos mais firmes, com vida-deprateleira mais extensa.

Na comparação do híbrido $\mathrm{H} 1$ com o híbrido H7 (Figura 1), que diferem entre si pela presença do gene alcobaça em heterozigose, verifica-se que o primeiro foi superior para uma atividade mais baixa da PME, o que sugere a manifestação do gene alc, que mesmo em heterozigose, proporciona maior potencial para conservação pós-colheita. Isto é particularmente evidente, quando se observa que em contrapartida o híbrido normal $\mathrm{H} 7$ apresenta atividade alta de PME.

O mRNA de PME e a atividade da enzima são detectados pela primeira vez em frutos com 10 a 20 dias de idade, e continuam a acumular até o estádio "de vez", quando atingem níveis vinte vezes mais altos, quando comparados com frutos de 10 dias de idade, declinando em seguida (Harriman et al., 1991). Isso também foi verificado neste estudo. A atividade mais alta de PME no estádio "de vez" coincidiu com a elevação da atividade de PG e com os primeiros sinais de mudanças na cor dos frutos. A função da PME é desmetilar o $\mathrm{C}_{6}$ de ácidos pectínicos possibilitando a ação da PG no processo de amaciamento de frutos. $\mathrm{O}$ melhoramento obteve sucesso 
com os híbridos H3, H8, H4 e H1, mantendo as suas atividades da PME em níveis mais baixos que a maioria dos híbridos avaliados em todos os estádios de amadurecimento, e particularmente, reduzindo o pico de atividade da PME no estádio "de vez" do amadurecimento. Nos três primeiros casos, trata-se de genótipos normais no locos alc, enquanto que no último trata-se de genótipo +/ alc, indicando que, embora seja possível aumentar a conservação pós-colheita em constituições genotípicas normais, o uso de heterozigotos alc (+/alc) pode ser uma estratégia viável.

As cultivares diferem entre si na seguinte ordem decrescente de atividade da PG: híbrido Ogata Fukuju > H4 > $\mathrm{H} 2>$ linhagem Tropicana-op $=\mathrm{H} 1>\mathrm{H} 5$ $=\mathrm{H} 6=\mathrm{H} 7>\mathrm{H} 8=\mathrm{H} 3$ (Figura 2). Variações entre os híbridos também foram observadas em menor escala para a atividade de PME (Figura 1). Isso se deve a um perfil de amadurecimento diferente entre as cultivares, nas quais essas enzimas são liberadas pela parede celular (PC) de forma e em tempos diferentes, e também, devido à natureza das substâncias pécticas e outros componentes da estrutura da parede celular.

O fato de os híbridos $\mathrm{H} 4$ e $\mathrm{H} 1$ terem apresentado atividade mais baixa de PME, e em contraste, apresentado atividade de $P G$ relativamente alta, pode ser explicado pela presença de pectinas com baixo grau de metoxilação. Além da capacidade genética desses híbridos de manterem níveis menores de $\mathrm{Ca}^{+2}$ nos tecidos, fazendo com que a PG atuasse mais intensamente sobre as pectinas. $\mathrm{O}$ $\mathrm{Ca}^{+2}$ tem papel relevante na ação da PME sobre as pectinas. Durante o amadurecimento do fruto, a atividade da PME resulta no aparecimento de grupos carboxílicos com carga $\left(\mathrm{COO}^{-1}\right)$, reduzindo o grau de esterificação e aumentando a densidade de cargas negativas ao longo da cadeia de pectina. Assim, a afinidade por ligação com o $\mathrm{Ca}^{+2}$ é aumentada, e essa ligação é considerada de natureza cooperativa, pois impede a ação da $\mathrm{PG}$ e conseqüentemente mantém a estrutura da parede celular (Burns e Pressey, 1987). Esse seria um dos possíveis mecanismos para explicar a baixa atividade da PG em cultivares com alta atividade da PME como ocorreu com o híbrido $\mathrm{H} 7$ e a testemunha,

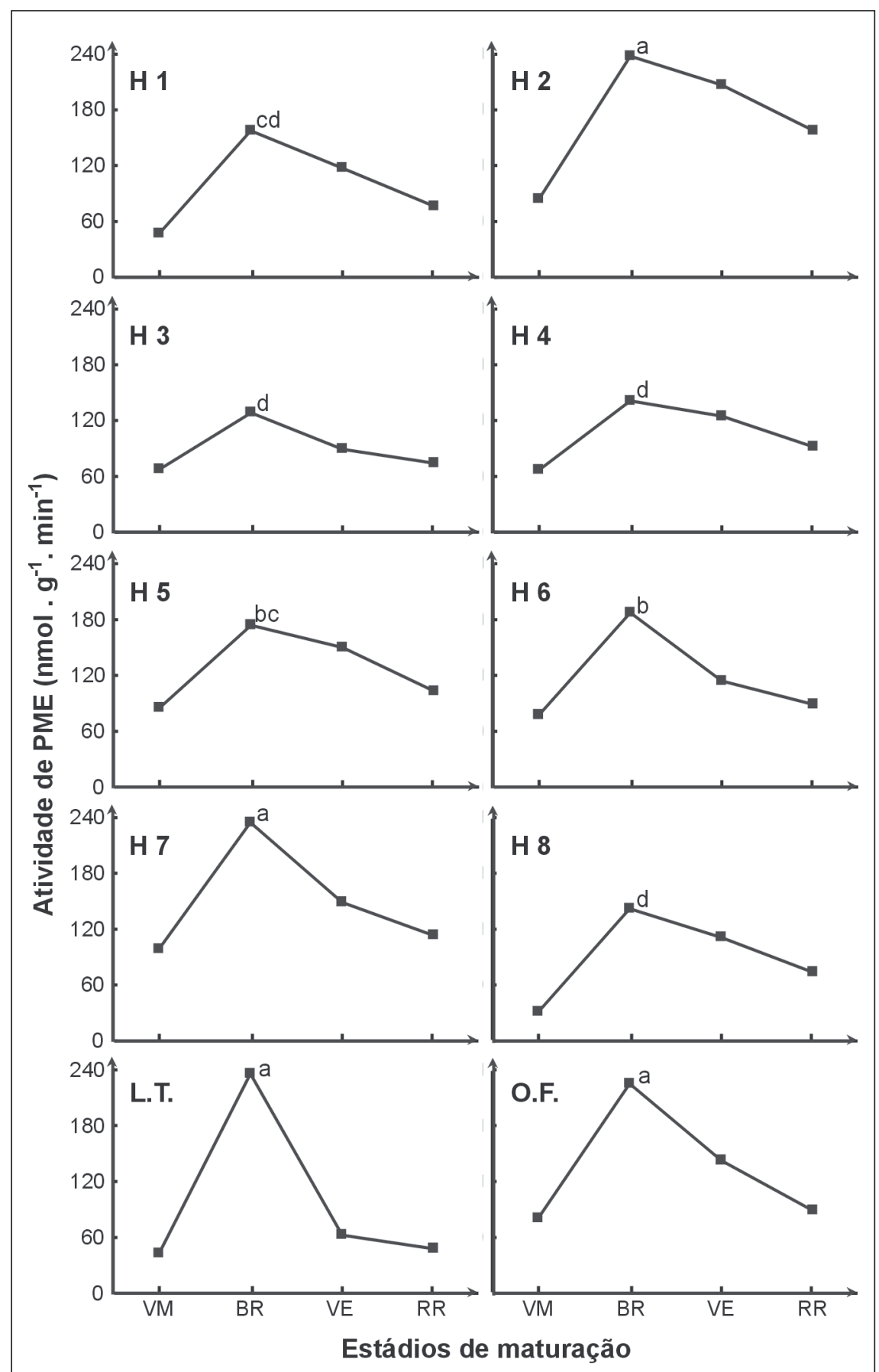

Figura 1. Atividade de pectinametilesterase nos estádios de maturação verde-maturo (VM), "de vez" (BR), maduro (VE) e vermelho-maduro (RR) de híbridos $\mathrm{F}_{1}$ de tomates do grupo multilocular. H1: $\mathrm{F}_{1}$ (BPX 308B hv $x$ BPX 127H); H2: $\mathrm{F}_{1}$ (BPX 308B hv $x$ BPX 105H); H3: $\mathrm{F}_{1}$ (BPX 308B hv $x$ Stevens); H4: $\mathrm{F}_{1}$ (BPX 308B hv $x$ Rotam-4); H5: $\mathrm{F}_{1}$ (BPX 308B hv $x$ BHRS-2-3); H6: $\mathrm{F}_{1}$ (BPX 308B hv $x$ Flórida 1B); H7: $\mathrm{F}_{1}$ (BPX 308B hv $x$ Tropicana); H8: $\mathrm{F}_{1}$ (BPX 308B hv $x$ Piedmont); L.T.: Linhagem Tropicana (op); O.F.: Híbrido $F_{1}$ Ogata Fukuju. Lavras-MG, UFLA, 1995.

As letras comparam os híbridos dentro do estádio "de vez", sendo que letras iguais eles não diferem entre si pelo teste de Duncan a $5 \%$

linhagem Tropicana-op no estádio "de vez". Híbridos com baixa atividade de PME e PG, como o H3 e H8, podem ocorrer devido à redução da tradução dos genes dessas enzimas ou ainda, à redução da tradução apenas da enzima PME associada ao alto nível de metoxilação das substâncias pécticas. 


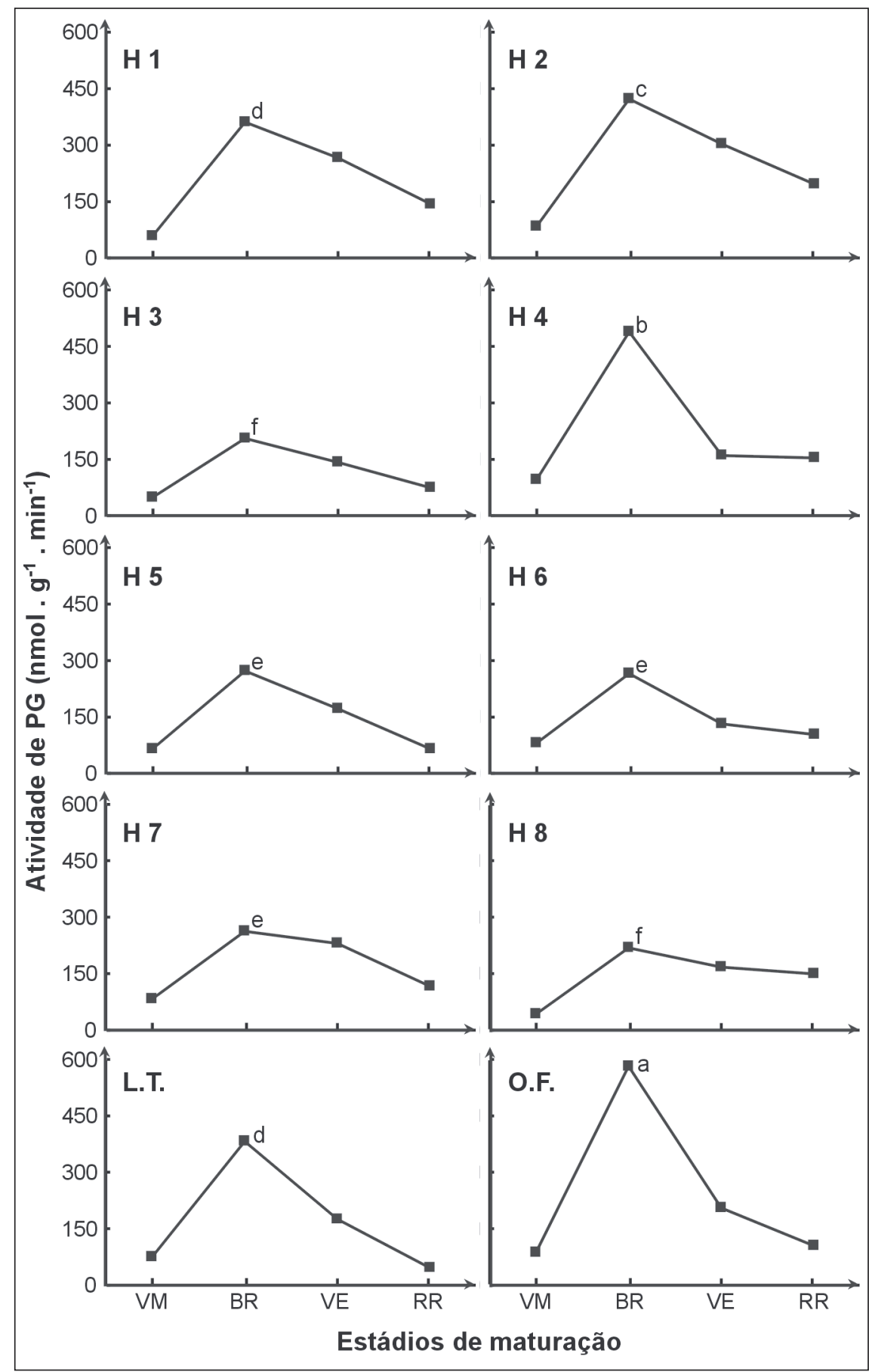

Figura 2. Atividade de poligalacturonase nos estádios de maturação verde-maturo (VM), "de vez" (BR), maduro (VE) e vermelho-maduro (RR) de híbridos $\mathrm{F}_{1}$ de tomates do grupo multilocular. H1: $\mathrm{F}_{1}$ (BPX 308B hv $x$ BPX 127H); H2: $\mathrm{F}_{1}$ (BPX 308B hv $x$ BPX 105H); H3: $\mathrm{F}_{1}$ (BPX 308B hv $x$ Stevens); H4: $\mathrm{F}_{1}$ (BPX 308B hv $x$ Rotam-4); H5: $\mathrm{F}_{1}$ (BPX 308B hv $x$ BHRS-2-3); H6: $\mathrm{F}_{1}$ (BPX 308B hv $x$ Flórida 1B); H7: $\mathrm{F}_{1}$ (BPX 308B hv $x$ Tropicana); H8: $\mathrm{F}_{1}$ (BPX 308B hv $x$ Piedmont); L.T.: Linhagem Tropicana (op); O.F.: Híbrido $\mathrm{F}_{1}$ Ogata Fukuju. Lavras-MG, UFLA, 1995.

As letras comparam os híbridos dentro do estádio "de vez", sendo que letras iguais eles não diferem entre si pelo teste de Duncan a 5\%

A baixa atividade da $\mathrm{PG}$ proporcionou híbridos mais firmes. Em trabalhos que comparam a textura de tomates contendo genes mutantes do amadureci- pais fatores na retenção da textura dos mutantes por períodos mais prolongados. O aumento da atividade da enzima PG pode ter efeito positivo sobre o conteúdo de licopeno (Mutschler et al., 1992), uma vez que ela é usualmente acumulada em paralelo com esse pigmento durante o amadurecimento. Entretanto, não foram observadas correlações entre a atividade da PG e o conteúdo de licopeno dos híbridos. $\mathrm{O}$ estado de heterozigose para crimson $\left(+/ \log ^{c}\right)$ nos híbridos estudados possivelmente amenizou os efeitos negativos da redução na atividade da PG.

Resultados semelhantes aos deste estudo foram obtidos por Nguyen et al. (1991), os quais constataram que a redução na atividade da PG em tomates mutantes não impediu a acumulação do pigmento licopeno, que foi acumulado em quantidades semelhantes à de frutos não mutantes, para menor atividade da PG.

O híbrido $(+/ a l c) \mathrm{H} 1$ teve atividade da PG no estádio “de vez” ligeiramente maior do que seu contraparente normal $(+/+)$, o híbrido $H 7$, ao contrário do que ocorreu em relação à atividade da PME. No entanto, essa diferença foi muito inferior à existente entre as atividades da PG de genótipos normais $(+/+)$ extremos, como entre os híbridos de atividade baixa (H3 e H8) e os de atividade alta (linhagem Tropicana-op e híbrido Ogata Fukuju), podendo ser considerada pouco importante. Assim, a heterozigose no locos alcobaça parece contribuir para a redução da atividade de PME, mas não da PG.

As atividades das enzimas PME e PG foram mais baixas nos híbridos $\mathrm{H} 3$, $\mathrm{H} 8$ e H1, quando comparadas às atividades dos outros híbridos durante todos os estádios de amadurecimento. A baixa atividade das enzimas PME e no caso dos dois primeiros, também de PG, levou a uma redução na despolimerização e solubilização das pectinas, resultando em maior textura. $\mathrm{O}$ desenvolvimento da cor, atributo considerado importante para qualidade dos frutos não foi influenciado pela baixa atividade da PME e da PG

A heterozigose do locos alcobaça promoveu aumento da textura, redução do teor de pectina solúvel e da relação pectina solúvel/pectina total, além de 
redução na atividade da $\mathrm{PME}$ (mas não da PG) no estádio "de vez", não parecendo ter efeitos deletérios sobre a qualidade dos frutos. Portanto, o gene alcobaça em heterozigoze pode ser uma alternativa viável para o melhoramento genético do tomateiro visando à melhor conservação em pós-colheita.

\section{LITERATURA CITADA}

AHRENS, M.J.; HUBER, D.J. Physiology and firmness determination of ripening tomato fruit Physiologia Plantarum, v.78, p.8-14, 1990.

ALY, M.A.A.; HOBSON, G.E.; BELTAGY, A.S Effect of introducing the mutant in rin allele on some characters of tomato fruit during storage. Acta Horticulturae, v.190, p.197-207, 1986.

BATISSE, C.; FILS-LYCAON, B.; BURET, M. Pectin changes in ripening cherry fruit. Journal of Food Science, v.59, n.2, p.389-393, 1994.

BITTER, T.; MUIR, H.M. A modified uronic acid carbazole reaction. Analytical Biochemistry, v.34, p.330-334, 1962.

BURNS, J.K.; PRESSEY, R. $\mathrm{Ca}^{+2}$ in cell walls of ripening tomato and peach. Journal of the American for Horticultural Science, v.112, p.783787, 1987.

CHITARRA, M.I.F.; CHITARRA, A.B. Pós-colheita de frutos e hortaliças. Fisiologia e manuseio. Lavras: ESAL/FAEPE, 1990. 320 p.

FISCHER, R.L.; BENNETT, A.B. Role of cell wall hydrolases in fruit ripening. Annual Review Physiology Plant Molecular Biology, v.42, p. 675 703, 1991.

GARDENER, R.G. "Piedmont" tomato. HortScience, v.20, n.5, p.960-961, 1985.
HARRIMAN, R.W.; TIEMAN, D.M.; HANDA, A.K. Molecular cloning of tomatos pectin methylesterase gene and its expression in rutgers, ripening inhibitor, nonripening, and never ripe tomatos fruits. Plant Physiology, v.97, p.80-87, 1991. JEN, J.J.; ROBINSON, M.L.P. Pectolytic enzymes in sweet bell peppers (Capsicum annuum L.). Journal of Food Science, v.49, p.1045-1087, 1984. KOCH, J.L.; NEVINS, D.J. Tomato fruit cell wall. I. Use of purified tomato polygalacturonase and pectinmethylesterase to identify developmental changes in pectins. Plant Physiology, v.91, p.816822, 1989.

KOCH, J.L.; NEVINS, D.J. Tomato fruit cell wall. II. Polyuronide metabolism in a nonsoftening tomato mutant. Plant Physiology, v.92, p.642-647, 1990.

LOBO, M.; BASSETT, M.J.; HANNAH, L.C. Inheritance and characterization of the fruit ripening mutation in 'Alcobaça' tomato. Journal of the American Society for Horticultural Science, v.109, n.5, p.741-745, 1984.

MABBETT, T.H. Control of texture in tomatoes nears reality. Agriculture international, v.41, n.7, p.239-240, 1989.

McCREADY, R.M.; McCOMB, E.A. Extraction and determination of total pectin, materials in fruits. Analytical chemistry, v.24, n.12, p.15861588, 1952.

MENCARELLI, F.; SALTVEIT JR., M.E. Ripening of mature-green tomato fruit slices. Journal of the American Society for Horticultural Science, v.113, n.5, p.742-745, 1988.

MITCHAM, E.J.; GROSS, K.C.; NG, T.J. Ripening and cell wall synthesis in normal and mutant tomato fruit. Phytochemistry, v.30, n.6, p.1777-1780, 1991.

MUTSCHLER, M.A.; WOLFE, D.W.; COBB, E.D.;

YOURSTONE, K.S. Tomato fruit quality an shelf life in hybrids heterozygous for the alc ripening mutant. HortScience, v.27, p.352-355, 1992.
NELSON, N.A. A photometric adaptation of Somoggi method for determination of glucose. Journal of Biological Chemistry, v.135, p.136-175, 1944.

NGUYEN, V.Q.; ASHCROFT, W.J.; JONES, K.H.; McGLASSON, W.B. Evaluation of $F_{1}$ hybrids incorporating the rin (ripening inhibitor) gene to improve the storage life and fruit quality of fresh market tomatoes (Lycopersicon esculentum Mill). Australian Journal of Experimental Agriculture, v.31, p.407-413, 1991.

PRATT, H.K.; WORMAN, M. Studies on the physiology of tomato fruits. III. The effect of ethylene on respiration and ripening behavior of fruit stored at $20^{\circ} \mathrm{C}$ after harvest. Proceedings of the American Soceity for Horticultural Science, v.81, p. 467-477, 1962.

PRESSEY, R.; AVANTS, J.K. Solubilization of cell walls by tomato polygalacturonases: effects of pectinesterases. Journal of Food Biochemistry, v.1, n.6, p.57-74, 1982.

RUSHING, J.W.; HUBER, D.J. Color and firmness of selected Florida-Grown tomato cultivars. Proceedings Florida State Horticulture Society, v.96, p.107-109, 1983.

SARRIÉS, G.A.; OLIVEIRA, J.C.V.; ALVES, M.C. SANEST. Piracicaba: CIAGRI, 1992. 80 p. (Série Didática Ciagri, 6).

SCHUCH, W.; KANCZLER, J.; ROBERTSON, D.; HOBSON, G.; TUCKER, G.A.; GRIERSON, D. BRIGHT, S.; BIRD, C. Fruit quality characteristics of transgenic tomato fruit with altered polygalacturonase activity. HortScience, v.26, n.12, p.1517-1520, 1991.

SOUZA, M.C.; SINGHA, S.; INGLE, M. Lycopene concentration of tomato fruit can be estimated from chromaticity values. HortScience, v.27, n.5, p.465-466, 1992.

TONG, C.B.S.; GROSS, K.C. Stimulation of ethylene production by a cell wall component from mature green tomato fruit. Physiologia Plantarum, v.80, p.500-506, 1990. 